\title{
Aproximaciones sobre el panorama epidemiológico en América Latina durante cinco siglos
}

\author{
Approaches of the epidemiological view in Latin America during five centuries
}

\author{
Dulce M. C. Delgadillo Álvarez* \\ Laboratorio Nacional de Servicios Experimentales, Centro de Investigación y de \\ Estudios Avanzados, Instituto Politécnico Nacional, México
}

*Autor al que se dirige la correspondencia: cdelgadillo@cinvestav.mx

Recibido: 02 de septiembre 2016 / Revisión: 18 de noviembre 2016 / Aceptado: 02 de febrero 2017

\section{Resumen}

$\mathrm{H}^{2}$

ace apenas 524 años la vida de los habitantes del continente americano cambió radicalmente, luego de la conquista y colonización europea. No se sabe mucho de la idea que tenían los pueblos prehispánicos sobre la salud pública; ni siquiera se sabe con certeza qué enfermedades padecían los nativos americanos antes del descubrimiento del continente. La historia de los pueblos surgidos de la conquista en relación a las políticas de salud ha estado marcada por los intereses políticos, pero sobre todo económicos de los países colonizadores. Este, es un recuento breve de esa historia.

\footnotetext{
Abstract

Since 524 years ago the life of the inhabitants of the Americas changed radically after the conquest and European colonization. Not much is known of the idea faced by prehispanic peoples on public health; not even know with certainty which diseases suffered American natives before the discovery of the continent. The history of peoples emerged from the conquest in relation to health policy has been marked by political but above all economic interests of countries colonizers. This is a brief account of that history.
} 


\section{Introducción}

En general, la edad se asocia a conocimiento y experiencia, pero también a pérdida de agilidad y belleza (de la Serna, 2003). En la mitología mexica o azteca, el sol era el dios principal y, si bien cada día nacía y envejecía para regenerarse al día siguiente, su ciclo de vida era de 52 años, tras los cuales tenía que morir para evitar una peligrosa entropía que podía conducir el mundo al caos. El ritual para representar esto consistía en cremar y enterrar solemnemente un haz de 52 cañas, que representaban los 52 años difuntos que se regenerarían en el espacio-tiempo de la muerte. De las cenizas de este ritual se sacaba el fuego nuevo, simbolizando que la muerte del tiempo propiciaba su propio renacer. De este modo, los mexicas establecieron la existencia humana en 52 años.

De acuerdo al historiador mestizo Fernando de Alva Ixtlilxóchitl, el rey tolteca no podía vivir más de 52 años y, si alcanzaba esa edad, tenía la obligación de suicidarse, pues como el sol tenía que morir antes de que la vejez consumiera su ser e hiciera imposible su regeneración (Alva de, 2016; Johansson, 2000). Es decir que, bajo la cosmovisión de este pueblo, lo que no moría y, por el contrario envejecía, encaminaba al mundo hacia su destrucción por lo que, en lugar de buscar maneras de prolongar la vida para demorar el cataclismo universal, los aztecas encontraron que la muerte juiciosamente infligida era el principio generador por excelencia. Morir a tiempo para no morir del todo y no permitir que el envejecimiento consumiera totalmente al ser (Johansson, 2000).

De hecho, en la cultura azteca se tenía como creencia que la forma más honorable de fallecer era, para los hombres, morir en la guerra, mientras que para las mujeres era durante el parto.

Pero, ¿qué pasaba con los cadáveres? Entre los aztecas, la forma de disponer de los muertos tenía que ver con el modo en que ésas personas hubieran fallecido. La mejor manera de deshacerse de los cadáveres era la cremación. Las excepciones para no incinerar un cuerpo y, enterrarlo, eran aquellas personas que hubieran tenido una muerte violenta, las que padecían alguna enfermedad incurable y los jóvenes de menos de 17 años (Harvey, 1981).

Definitivamente, el dejar exentas de ser incineradas a las personas que murieron por un padecimiento incurable quizá no fue una de las mejores medidas de salud pública. A pesar de esto, las crónicas de los conquistadores describen la ciudad y la sociedad azte- ca, con una limpieza excepcional. Para la primera se menciona que se contaba con mecanismos de disposición de basura y excrementos humanos, sistemas de drenaje, de abastecimiento de agua y saneamiento de los canales que atravesaban la ciudad de Tenochtitlán. En cuanto a la población, no existen en los registros arqueológicos e históricos evidencias de que ésta haya sufrido epidemias o enfermedades endémicas crónicas (Harvey, 1981).

Dada la falta de información que nos permita conocer con fidelidad la situación de salud de las poblaciones precolombinas, es trascendente conocer la historia de cómo los pueblos americanos fueron adquiriendo y cambiando sus políticas de salud de acuerdo a los lineamientos que su situación política y económica les imponía. El objetivo de este ensayo es hacer un recuento breve de esa historia.

\section{Contenido}

\section{Panorama de la salud pública durante la con-} quista y colonización de América

El panorama de la salud de los habitantes de la América precolombina cambió radicalmente luego de la llegada de los conquistadores. A pesar de muchas discrepancias, se estima que el número de pobladores de los centros urbanos más poblados, esto es, México y Perú era de 25 y 10 a 15 millones de personas, respectivamente (Malamud, 2014). La llegada de los conquistadores significó, entre muchas otras cosas, la exposición de los pueblos prehispánicos a patógenos desconocidos en tierras americanas y enfermedades como la viruela, el sarampión, la gripe, el tifus, la fiebre amarilla y la malaria, hicieron estragos en la población reduciéndola, a finales del siglo XVI, a un $10 \%$ de sus cifras originales (Guerra, 1988; Sánchez, 2011).

Lamentablemente, los estudios sobre la colonización de América se han centrado en aspectos militares, políticos, económicos y éticos; los reportes sobre cuestiones científicas y sanitarias son muy escasos (Cordero, 2001). Esto hace de la epidemiología en el continente americano prehispánico solo una hipótesis que se deduce de pocos vestigios arqueológicos pues, en caso de haber existido, los registros de enfermedades que sufría la población indígena así como los métodos de curación de las mismas basados en plantas medicinales, se perdieron durante la conquista, aunque, cabe mencionar que en 1571, la corona española envió al médico Francisco Hernández con la encomienda de realizar un 
estudio sistemático de la botánica médica de la Nueva España. La obra de Hernández comprendió la descripción de casi tres millares de especies de plantas. Los escritos enviados por Hernández al rey Felipe II y de la que Nardo Antonio Recchi se encargó de realizar una selección para su publicación, fueron depositados en la biblioteca de El Escorial, donde permanecieron hasta que fueron destruidos por un incendio en 1671. Los borradores de estos escritos se conservan repartidos en la Biblioteca Nacional y la Biblioteca del Ministerio de Hacienda de España (López \& Pardo, 1996). Pese a la importancia de esta obra en la actualidad, la única certeza que se tiene es la convicción de que la farmacopea mexicana prehispánica estaba basada exclusivamente en el empirismo (Harvey, 1981).

Durante la conquista, en todo el continente americano, el panorama epidemiológico negativo se complementaba con hambrunas, marginación social, trabajos forzados a los que eran sometidos los indígenas y enfrentamientos entre nativos y colonizadores.

Sin embargo, en las ciudades ya establecidas o en aquellas que se fundaban a lo largo del continente, los conquistadores comenzaron a ver la necesidad de combatir o evitar las epidemias que azotaban a la población indígena pues esta representaba su más importante fuerza de trabajo. Una medida adoptada para esto, fue la creación de hospitales que eran sitios de aislamiento y cuidado de pobres y enfermos o sospechosos de tener alguna enfermedad. El primer hospital de la colonia se construyó entre 1503 y 1506 en la isla La Española, que hoy en día comprende dos países: República Dominicana y Haití; actualmente de este hospital nombrado San Nicolás de Bari sólo se conservan las ruinas. El segundo hospital de América fue el Hospital de Jesús Nazareno, fundado en la Ciudad de México-Tenochtitlán entre 1524 y 1527 y, a diferencia del anterior y con casi 500 años de actividad hospitalaria, continúa con sus funciones, aunque claro, actualizado (Barrionuevo, 1975).

Otras dos medidas seguidas por los colonizadores fueron que, en el caso de la muerte de los enfermos contagiosos, enterrar los cadáveres profundamente $\mathrm{y}$, someter a cuarentena a los barcos que arribaban a los puertos de América y que eran sospechosos de transportar enfermos. Poco a poco, los conquistadores se ocuparon de abastecer a las ciudades de agua limpia, así como manejar los desechos para evitar malos olores, putrefacciones, ambientes insalubres y presencia de fauna dañina (Fajardo-Ortiz \& Ferrer-Burgos, 2003). También, comenzaron a hacerse registros sobre datos de población, pero todos fueron irregulares e incompletos.
Los datos sobre nacimientos, bautizos, matrimonios, muertes y sepulturas debían inscribirse en las parroquias y esto no siempre ocurría. Además, en cuanto a las defunciones, se registraba el nombre del fallecido, su estado civil, a veces si existía un testamento, si había recibido los santos sacramentos, la fecha de entierro pero no la de la muerte, así como tampoco el padecimiento causante de la misma.

Fue después de 1720 que en ciudades como Buenos Aires, Lima, Nueva España y algunas de Cuba se hicieron mejores registros demográficos, pero que no eran suficientes para evaluar los servicios otorgados y optimizar las condiciones de vida de la población, pues no existía un modelo de atención médico-sanitario definido, así como comprensión ni conocimientos eficaces sobre la prevención, origen y difusión de las enfermedades transmisibles (Fajardo-Ortiz \& Ferrer-Burgos, 2003). Los colonizadores también comenzaron a documentar las, hasta entonces, desconocidas enfermedades y las condiciones climáticas que les servían de soporte llegando a la conclusión que las enfermedades eran características de los lugares, lo que se explicaba por la poca movilidad de las poblaciones durante el período colonial. Un poco más tarde este nexo entre el ambiente y la salud quedaría plenamente comprobado con el trabajo de los médicos Carlos J. Finlay y Carlos Chagas, quienes descubrieron, respectivamente, los vectores y los mecanismos de transmisión de dos enfermedades verdaderamente devastadoras: la fiebre amarilla y la enfermedad de Chagas. Esto aún antes de que los agentes patógenos de las mismas se identificaran (Iñiguez \& Barcellos, 2003).

\section{Aspectos generales de la salud pública en América Latina y México independientes}

A partir de 1809, los países de América Latina iniciaron las luchas que los llevaron a obtener su independencia. Durante casi todo el siglo XIX y principios del $\mathrm{XX}$, el continente estuvo enfrascado en enfrentamientos armados. Como consecuencia de las guerras independentistas, hubo desplazamientos de grandes grupos de población civil, hambrunas y pérdida de hábitos de higiene que hicieron vulnerables a muchos individuos. Afortunadamente, enfermedades como la viruela habían comenzado a ser controladas con la aplicación de la vacuna antivariólica, que en 1804 fue llevada de España a América en una expedición sanitaria encabezada por el médico Francisco Xavier Balmis (Micheli de \& Izaguirre-Ávila, 2011). En México, durante la guerra 
de independencia hubo reportes de brotes de viruela, sarampión, fiebre amarilla y fiebres de origen desconocido, pero ninguna de estas enfermedades alcanzó, en esa época, la magnitud de una epidemia (Viesca-Treviño, 2010). Sin embargo, este no fue el caso del cólera.

Esta enfermedad conocida como cólera morbus es una infección intestinal causada por la ingestión de la bacteria Vibrio cholerae. En 1817, se presentó una primera pandemia de cólera que se inició en la región de Bengala en el subcontinente Indio. Entre 1829 y1851, una segunda pandemia originada probablemente en Astrakan, ciudad situada al sur de la Rusia europea, en China o en la misma India, se propagó por Asia y gran parte de Europa y llegó a América entrando por la provincia de Quebec en Canadá. A partir de aquí se esparció por Estados Unidos. En 1833, el cólera llegó a Cuba aparentemente desde España de allí pasó a las costas de Guyana y en 1837 apareció en Nicaragua y Guatemala. En México la enfermedad se presentó también en 1833, quizá traída desde Nueva Orleans o La Habana (González, Casanova, \& Pérez, 2011; Ramírez, 2016; Tovar \& Bustamante, 2000). Durante este período y dadas las condiciones de insalubridad reinantes, el cólera se extendió en todo el continente causando miles de muertes. Tan sólo en México se estima que en estados como Veracruz, Guanajuato, Durango, Oaxaca, y las ciudades de México, Guadalajara y Puebla, sucumbió el 5.3, 4.2, 2, 2, 4.8, 7.8 y 8\%, de la población, respectivamente (Iracheta \& Lagunas, 1998; Prieto-Miranda, Jiménez-Bernardino, Guerrero-Quintero, \& Mora-Sota. 2012).

Desde 1817, en el mundo se han presentado siete pandemias de cólera. Todas han alcanzado al continente americano. Durante los primeros brotes y, dado que la comunicación con el resto del mundo ya no era nula, se tenía el conocimiento de que la enfermedad era propagada en lugares con poca higiene donde el agua era fácilmente contaminable. Y, países como México y Guatemala, por ejemplo, establecieron Juntas de Sanidad con el propósito de coordinar actividades para contener la epidemia y vigilar el cumplimiento de medidas higiénicas elementales en la población; entre estas acciones estaban también proporcionar atención a los enfermos, hacer registros oficiales de los casos que se iban presentando y reubicar cementerios lejos de las zonas de mayor concentración de población (Ramírez, 2016; Tovar \& Bustamante, 2000).

Lamentablemente, a pesar de que el saneamiento y la potabilización de agua han mejorado sustancialmente, el cólera sigue presente en el mundo. La Organización Panamericana de la Salud (OPS) y la Orga- nización Mundial de la Salud (OMS), llevan registros semanales de los casos de cólera que se presentan en el continente. En el informe de la actualización epidemiológica del cólera de las semanas 1 a 43 de 2016, cuatro países de América (Ecuador, Haití, México y la República Dominicana) reportaron 35,755 casos. De estos, el 97\% correspondió a Haití. Para 2017, entre las semanas epidemiológicas 1 y 14 se notificaron 4,871 casos en Haití incluidas 69 defunciones; en República Dominicana durante el mismo período se reportaron 62 casos sospechosos de esta enfermedad incluidas dos defunciones. En Ecuador y en México no se reportaron casos en el mismo lapso de tiempo (OMS, 2017; OPS, 2017).

Pero volviendo a la historia aquí relatada, podemos decir que la salud pública comenzó a establecerse en América Latina luego de que los países que la conforman alcanzaran un cierto nivel de estabilidad política y social y, si bien estos eran dos factores de elevada trascendencia, fue la economía el principio que determinó el rumbo en la vida de las nuevas naciones. Así, los servicios de salud de los países de la región se ajustaron a las necesidades de una producción capitalista destinada al comercio exterior, pues muchos de ellos establecían e incrementaban el comercio internacional y, sus socios comerciales, estaban interesados en el control de las enfermedades que podrían afectar a la población trabajadora y con ello a sus ingresos. Movidos por sus intereses económicos sobre la zona latinoamericana, Estados Unidos y algunos países europeos como Gran Bretaña y Francia impusieron fuertes medidas de saneamiento. Los primeros países de América Latina en crear unidades estatales de sanidad fueron Argentina, Uruguay y Brasil (García, 1981). En México este hecho tuvo lugar también al final del siglo XIX, en la época conocida como porfiriato, misma que se prolongó a la primera década del siglo XX y que fue interrumpida por la Revolución de 1910. En el México porfiriano, la salud pública se concentró en enfermedades como viruela, sarampión, tos ferina, escarlatina, peste, cólera e influenza, además de la fiebre amarilla, paludismo, tuberculosis y sífilis. El personal dedicado al servicio sanitario del porfiriato estaba atento a los adelantos de las ciencias médicas en el mundo e influyó grandemente en la promulgación de leyes sanitarias que cambiaban conforme lo hacían las teorías médicas (Carrillo, 2002).

El final del siglo XIX y el principio del XX, fue el período de la transformación de la medicina como ciencia con la introducción de la asepsia y la anestesia, así como descubrimientos importantísimos como: los antibióticos por Alexander Fleming; los mecanismos 
que controlan la respuesta inmune en el cuerpo humano descritos inicialmente por Frank MacFarlane Burnet; las bases genéticas de la respuesta inmune explicadas por Davis, Dausset y Benacerraf que fueron la base para la obtención de anticuerpos monoclonales por Milstein, Köler y Jerne. En 1895 Röntgen descubrió los Rayos X y Bequerel la radiactividad natural en 1896. Los años que siguieron estuvieron llenos de hallazgos en este campo pero no fue hasta el fin de la Segunda Guerra Mundial que los isótopos radiactivos se emplearon con fines diagnósticos y terapéuticos (Pruna, 2006). En 1900, surgió la genética como ciencia con el descubrimiento de los trabajos de Gregor Mendel publicados en 1866 y los postulados de la teoría cromosómica de la herencia de Thomas Hunt Morgan (Morgan, 1915). Posteriormente surgió la genética molecular con la demostración de Avery en 1944 de que el ácido desoxirribonucléico $(\mathrm{ADN})$ era el portador de la información genética (Avery, MacLeod, \& McCarty, 1944). La dilucidación de la estructura molecular del ADN en 1953 abrió todo un campo de investigación en la biología molecular y la ingeniería genética (Franklin \& Gosling, 1953; Watson \& Crick, 1953).

Todos estos descubrimientos y avances en la ciencia y la medicina tuvieron gran influencia en el mundo entero. Sin embargo, en la América Latina independiente estos acontecimientos coincidieron temporalmente con una inestabilidad política caracterizada por regímenes dictatoriales que tuvieron por supuesto repercusión en las políticas de salud pública. De hecho de 1950 a 1990, la mayoría de los países de la región vivieron bajo dictaduras y solo en algunos de ellos como Costa Rica y Uruguay, se ha mantenido un gobierno democrático arraigado en el primero, desde mediados del siglo XIX, $\mathrm{y}$ en el segundo, instalado en el inicio del siglo XX (Ruiz \& Morales, 2015; Santiso, 2006).

Pero como señalamos, América Latina no estaba ya alejada del mundo y el intercambio comercial era constante y, con él la diseminación de patógenos traídos de lugares muy lejanos. Uno de estos patógenos era el ya conocido virus variola, causante de la viruela. Como se mencionó antes, esta enfermedad causó grandes estragos en la población del nuevo continente y, a la par, seguía siendo un flagelo difícil de controlar en otras partes del planeta. En 1796 el médico inglés Edgard Jenner descubrió la vacuna antivariólica que comenzó a aplicarse en la población inglesa como medida de prevención de este padecimiento. También hemos mencionado que esta vacuna fue llevada a América por el médico Francisco de Balmis en lo que podría considerarse como el inicio de la erradicación de la enfermedad en el continente. Dados los efectos devastadores de la viruela, a nivel mundial se realizaron campañas de vacunación permanentes con el fin de acabar con ella. El primer organismo en el mundo que inició una campaña de erradicación de la enfermedad fue la OPS en 1950 pues, hacia 1940, la vacuna había podido ser liofilizada y con ello llevada sin perder sus propiedades inmunoprotectoras a gran parte del continente americano. La erradicación de la viruela representa la hazaña más importante en la historia médica de la humanidad, ya que es la única enfermedad combatida a escala mundial. Los primeros países de América Latina que lograron controlar la viruela fueron: Guyana Francesa en 1904, Costa Rica en 1920, Panamá en 1922, Nicaragua en 1924, Belice en 1939 y Guatemala y México en 1951 (Franco-Paredes, Lammoglia, \& Santos-Preciado, 2004), así como Perú en 1957 (Quirós, 1996). En la década de 1960, las campañas de inmunización global, la vigilancia y las medidas de prevención de la enfermedad emprendidas por la OMS se intensificaron y dieron sus mejores frutos al ser registrado el último caso de viruela contraída de manera natural en un habitante de Somalia en 1977. En 1980, la OMS declaró la erradicación absoluta de la enfermedad en el planeta.

Otro éxito en cuanto al control de una enfermedad infecciosa es el caso de la poliomielitis o polio. Esta enfermedad causada por poliovirus ataca principalmente a niños por lo que se le llama también poliomielitis infantil. En 1991 se reportó el último caso de poliomielitis en América y, en 1994, la Comisión Internacional para la Certificación de la Erradicación de la Poliomielitis declaró que el virus salvaje de la polio se había interrumpido en el continente (OPS/OMS, 2016). No obstante, esta enfermedad no ha sido erradicada en otras partes de mundo y países como Camerún, Afganistán, Etiopía, Somalia y Nigeria, entre otros siguen presentando casos de este padecimiento por lo que la OPS declaró en 2014 que el poliovirus salvaje no ha dejado de ser una Emergencia de Salud Pública de Importancia Internacional y recomienda que los niveles de cobertura de vacunación contra la polio se mantengan en el continente además de la vigilancia adecuada de la parálisis flácida aguda para mantener el estatus de la región libre de esa enfermedad. Asimismo, sugiere a todo viajero que salga del continente americano y se dirija a alguno de los países que presentan la infección que se inmunice antes de emprender el viaje (Dye, 2014; OPS, 2013). 
En México, ya con cierta aunque frágil estabilidad política, desde el final del porfiriato y durante la época postrevolucionaria se crearon las instituciones de salud más importantes del país como, entre otros, el Hospital General de México en 1905, el Instituto Mexicano del Seguro Social en 1935, la Secretaría de Salubridad y Asistencia en 1943 (actualmente Secretaría de Salud) y hospitales como el Centro Médico Nacional, el Centro Médico 20 de Noviembre, el Hospital Central Militar y el Hospital de la Raza (Flisser, 2009). Estas instituciones han prevalecido sobrepasando incluso un período de casi 70 años de gobierno del mismo partido político (Santiso, 2006).

\section{Salud pública de América Latina y México en el siglo XX}

Uno de los factores que más ha impactado la salud pública de la población de América Latina ha sido el crecimiento demográfico. Por ejemplo, en el año de 1900, México contaba con una población de 13 millones de personas, en 1950 la población casi se duplicó alcanzando 25.8 millones; en 2015 el registro fue de 119,530,753 habitantes (Flisser, 2009; Instituto Nacional de Estadística y Geografía, 2015). Este incremento en el número de habitantes es afectado, además, por el evidente envejecimiento de la población y será el cambio demográfico más notorio del siglo XXI requiriendo además políticas y programas en aspectos como la atención médica, la seguridad económica, el apoyo en el ámbito familiar, las relaciones generacionales y la necesidad de nuevas normas sociales (Ham, Nava, \& Torres, 2011). Sin embargo, es innegable que, aunque insuficiente, durante los últimos 50 años ha habido en América Latina un incremento en el nivel educativo de la población, por lo que se han mejorado las condiciones económicas; gracias a los adelantos en la medicina se ha disminuido la mortalidad infantil, y también se ha desarrollado un proceso muy rápido de urbanización y una integración cultural de los pueblos.

Estos son sólo algunos factores que han contribuido a que las mujeres tengan mejor preparación y desarrollo personal, que dejen la imagen tradicional de la madre ama de casa y aspiren y ocupen puestos que estaban sólo destinados a los hombres. Los cambios en la expectativa de vida profesional de las mujeres ha propiciado un descenso en la fecundidad en América Latina y el Caribe en las mujeres adultas y ha sucedido, además, con el apoyo de los gobiernos y, en general, de organizaciones no gubernamentales como MexFam en México, la Asociación Pro-Bienestar de la Familia de Guatemala, la Asociación Civil de Planificación Familiar de Venezuela, la Jamaica Family Planning Association y el Centro de Investigación, Educación y Servicios de Bolivia, entre otras (International Planned Parenthood Federation [IPPF], 2014).

Pero, a pesar de estos resultados positivos, la región presenta la mayor fecundidad adolescente en el mundo después del África subsahariana y se estima que será la más alta hacia el 2020 y se mantendrá en ése rango hasta el 2100. Estos datos surgen de aquellos que indican que una tercera parte de los embarazos corresponden a menores de 18 años, siendo casi un 20\% de estas menores de 15 años. Entre los países americanos con mayores porcentajes de madres jóvenes están: Nicaragua con $28 \%$, Honduras con $26 \%$, República Dominicana con $25 \%$, Guatemala y El Salvador con $24 \%$, Ecuador con $21 \%$ y Bolivia y Colombia con $20 \%$. Lamentablemente, estos embarazos suelen ser producto de violencia sexual debido a la vulnerabilidad de las niñas y adolescentes que muchas veces están expuestas a violencia física, psicológica y económica. Por otro lado, existe además la reticencia institucional tanto de la sociedad como de la familia para reconocer a los y las adolescentes como sujetos sexualmente activos restringiendo con ello su acceso a métodos de planificación familiar y a conocimientos y prácticas sexuales seguras. Sin embargo, en muchos países del continente existen programas para atender temas de salud sexual y reproductiva de jóvenes como las Casas Municipales de la Adolescencia y Juventud de Nicaragua y el Programa de Atención de Madres Adolescentes de Argentina (United Nations International Children's Emergency Fund [UNICEF], 2014).

En referencia a este punto, gobiernos de países como México, Costa Rica y Panamá, por ejemplo, han incluido en su legislación estrategias, programas y marcos legales para la implementación de una paternidad responsable en los que se enfatizan los derechos reproductivos de las personas con una participación masculina mayor desde la concepción misma de los hijos hasta su manutención y cuidado. Esto, porque el papel masculino en el cuidado de los hijos es de relevancia trascendental pero muchas veces ignorado por los mismos hombres. Así, con el fin de involucrar más al sector masculino, se han discutido temas de interés para los hombres como la salud del aparato reproductor (para la prevención y el control de enfermedades como cáncer de próstata o de testículos); control de fecundidad y planificación familiar (para no dejar la 
responsabilidad total en la mujer), enfermedades de transmisión sexual; salud psicosexual y procreación y paternidad (que contemplan tanto la conducta irresponsable de algunos hombres con el desconocimiento de dicha paternidad evitando obligaciones, como la acción de padres que reclaman sus derechos con respecto a sus hijos) (Santos, 2010).

Por otro lado, al igual que el resto de América Latina, México ha sufrido severas crisis económicas. Igualmente, la cantidad, la velocidad y las rutas de movilización de los grupos de población, así como la urbanización y el intercambio intercontinental se han incrementado significativamente. Las mezclas interétnicas que se han dado en el continente desde la llegada de los europeos y africanos con nativos americanos, también se deben considerar no sólo por un interés histórico sino por ser una herramienta en el estudio de las enfermedades hereditarias actuales, pues es obvio que éstas son el resultado de una combinación genética entre esos grupos de población (Salzano \& Sans, 2014).

Asimismo, para establecer políticas de salud adecuadas para la población es fundamental tener datos socioeconómicos y demográficos de la misma. Y, si bien este tipo de información es básica para el diseño de planes y programas de salud que puedan ser aplicables en cada país, no en todos ellos se realiza debido a problemas como el costo, intereses propios de cada gobierno y la logística.

No obstante las limitaciones, los países de América Latina han logrado tener esquemas de control de enfermedades, en otros tiempos catastróficas. Un ejemplo de que una buena estrategia de salud pública puede controlar una enfermedad, se observa en Cuba. Este país fue severamente afectado por la tuberculosis durante todo el siglo XIX y las primeras seis décadas del XX. De hecho, la incidencia de esta enfermedad, en 1954 , era de 35.9 por cada 100,000 personas y en 1962 de 40.1 por cada 100,000 habitantes y disminuyó a 6.1 por cada 100,000 personas en 2012. La estrategia seguida por el gobierno cubano en la lucha contra este padecimiento comprendió objetivos muy concisos, como prevenir la transmisión del agente infeccioso mediante la vacunación y la profilaxis; evitar las secuelas de la enfermedad en la gente infectada; tener un control amplio y estricto sobre la revisión médica de la población y aplicar métodos y técnicas simples y efectivas tanto para el diagnóstico, detectando casos en etapas tempranas, como para el tratamiento de la enfermedad, cuidando de los enfermos en los lugares adecuados construidos especialmente para ese propósi- to, así como capacitar al personal encargado de atender a los pacientes (Beldarraín, 2015).

Otro caso digno de mencionar también relacionado con Cuba, es el control que el país ha tenido en cuanto al cólera. Como señalamos antes, la enfermedad se introdujo en la isla en 1833 y desde ese año hasta 1867 causó miles de muertes. Luego de esta fecha, los registros de la incidencia del padecimiento no son muy claros, sin embargo, después del triunfo de la Revolución y gracias al desarrollo alcanzado en el área de salud pública, Cuba no reportó casos de la enfermedad por lo menos hasta 2011 (González, Casanova, \& Pérez., 2011).

Cabe mencionar también, que durante el siglo XX y los años transcurridos del XXI, la industria farmacéutica para el tratamiento de enfermedades como las mencionadas: tuberculosis y cólera, ha tenido un desarrollo significativo. Así, en 1944 se descubrió la estreptomicina que pudo ser utilizada para el tratamiento de la tuberculosis. Otros medicamentos para combatir la enfermedad son el ácido paraaminosalicílico probado por vez primera en 1945, la isoniacida, la rifamicina y la pirazinamida introducidos en 1952, 1968 y 1972, respectivamente. Además, por supuesto del desarrollo de la vacuna BCG en 1921 (Pérez, García, Pérez, \& Samper, 2009).

En cuanto al cólera, el tratamiento más adecuado es la rehidratación inmediata de las personas afectadas, así como la aplicación de antibióticos. Actualmente se han desarrollado tres vacunas contra esta enfermedad que han sido precalificadas por la OMS: Dukoral ${ }^{\circledR}$, Shanchol ${ }^{\mathrm{TM}}$ y Euvichol ${ }^{\circledR}$. La administración de estas vacunas proporciona una protección del $65 \%$ contra la bacteria (OMS, 2016).

Además de estos éxitos, y dado que Cuba ha estado sujeta a una severa y prolongada crisis económica, la políticas del gobierno de ese país han logrado reducir la tasa de mortalidad infantil hasta 4 por cada 1,000 niños menores de 1 año y tener un esquema de vacunación que cubre el $100 \%$ de su población. Uno de los factores que ha ayudado a este país a alcanzar estas metas es, desde luego, el pueblo mismo como la parte más importante y la ayuda económica que organizaciones internacionales le han prestado. Una de estas organizaciones es Gavi (Global Alliance for Vaccines and Immunisation) creada en el 2000 para acelerar la introducción de vacunas nuevas e infrautilizadas en países con bajos recursos económicos, seleccionados por el ingreso per cápita establecido por el Banco Mundial (Kallenber et al., 2016). De América Latina además 
de Cuba, los países que han sido apoyados por Gavi son Bolivia, Honduras, Guyana, Nicaragua y Haití; sin embargo, los resultados obtenidos en estos países no han sido tan exitosos como el de Cuba. Un ejemplo es Guyana que tiene un índice de mortalidad infantil de 32 por cada1,000 niños menores de 1 año $y$, a pesar de que tiene un esquema de vacunación elevado no alcanza al $100 \%$ de sus habitantes (Global Alliance for Vaccines and Immunisation [Gavi] The Vaccine Alliance, 2016).

Sobrepasando los cambios de regímenes políticos y sobrellevando las crisis económicas, muchos grupos de investigación de países de América Latina han realizado esfuerzos conjuntos, llevando a cabo estudios multinacionales que abordan problemas comunes de la región. Así, se han creado sociedades como, entre muchas otras, la Asociación Médica Latinoamericana de Rehabilitación fundada en 1961 y la Sociedad Latinoamericana de Investigación Pediátrica fundada en 1962 que, desde su establecimiento, continúan respondiendo a un requerimiento común como desafiar los paradigmas del momento, generar evidencia utilizando la mejor metodología científica y aprovechar la riqueza de la discusión transdisciplinaria (Asociación Médica Latinoamericana de Rehabilitación, 2016; Guimarey \& Ferrero, 2014). Otro ejemplo más reciente, se dio en el 2013, cuando se creó una red internacional multinacional con 20 países latinoamericanos denominada Red de Enfermedad de Kawasaki en América Latina (Rekamlatina) con el propósito de tener un mejor y mayor conocimiento de la epidemiología de la enfermedad de Kawasaki en el continente (González-Mata, Ulloa-Gutiérrez, Brea del Castillo \& Tremoulet, 2013). En el caso de esta enfermedad multisistémica con vasculitis de pequeños y medianos vasos que afecta principalmente a niños menores de 5 años y cuya patogenia se desconoce, la importancia de este tipo de acciones es que se tengan datos epidemiológicos que puedan convencer a las autoridades de salud de la importancia de la enfermedad y la necesidad de tener tratamientos disponibles y accesibles para los niños de la región (Ulloa-Gutiérrez, Salgado, \& Tremoulet, 2014).

Por otro lado, estudios sobre problemas comunes de la zona como la economía, la desnutrición y el aumento en las tasas de obesidad están orientados a proporcionar a las autoridades competentes los elementos necesarios para tomar las medidas pertinentes en el diseño de programas de salud adecuados y encaminados a controlar los problemas mencionados. Esto, porque es conocido que casi una cuarta parte de la población en América Latina es obesa y la prevalencia de esta enfermedad ha aumentado en una magnitud mayor en México, Argentina y Chile (Fisberg et al., 2015). Respecto a los problemas de nutrición, se ha encontrado que los países con el más alto nivel de desnutrición son Haití, Honduras, Guatemala y Honduras, mientras que Argentina, Brasil y Costa Rica tienen el nivel más bajo (Kac \& García, 2010). Y, en relación con la economía, es innegable que este es el factor más importante en toda la región. El desempleo, la inflación y el producto interno bruto de cada nación afectan directamente a su población. Sin embargo, es la falta de educación, empleo y por tanto de solvencia económica, la causa más perjudicial para la salud de la población porque se asocia con un incremento de problemas psicológicos y comportamientos malsanos debido, en parte, a que la falta de recursos monetarios suficientes conducen a una nutrición deficiente y un acceso reducido a una atención médica apropiada y es, además, un elemento clave en el aumento de suicidios (Williams, Gilbert, \& Zeltner, 2016).

\section{Conclusiones}

La condición de salud de una población es el resultado de una combinación compleja de factores sociales, biológicos, educativos y financieros. Como hemos visto, en América Latina desde la época de la conquista, la historia de la salud pública ha estado sometida a los lineamientos económicos y políticos de los países que han tenido y tienen injerencia en la región. A pesar de los avances que sobre la materia se han realizado en cada país, es evidente que en muchos de ellos todavía hacen falta políticas de salud pública decisivas para tener el control completo del bienestar sanitario de sus ciudadanos pues si bien, la ayuda proporcionada por organizaciones internacionales es importante, es innegable que es responsabilidad de los gobiernos suministrar a la gente las condiciones sanitarias óptimas para crecer y desarrollarse. Indudablemente es necesario también que los gobiernos presten atención especial a las políticas de educación de sus pueblos destacando por supuesto una educación sexual que comience desde la niñez y que se enfatice en la adolescencia para evitar embarazos tempranos. De este modo se incentivaría que los jóvenes, principalmente las niñas, alcanzaran una madurez biológica, psicológica, profesional y laboral que les permitiera desarrollarse como personas productivas. Desde luego que esta no es una tarea fácil pues se deben considerar factores de tradición y cultura de cada pueblo que influyen en la toma de decisiones sobre 
los esquemas de planificación familiar y crecimiento personal. Así, podemos concluir que las mejoras en aspectos tan importantes como el educativo, el laboral y por tanto económico, así como el nutricional, sin duda tendrían un beneficio en la salud de los habitantes del continente.

\section{Referencias}

Alva de, F. (2016). Historia de la Nación Chichimeca. Barcelona, España: Red Ediciones SL.

Asociación Médica Latinoamericana de Rehabilitación. (2016). Recuperado de http://www.portalamlar. org

Avery, O., MacLeod, M., \& MaCarty, M. (1944). Studies on the chemical nature of the substance inducing transformation of Pneumococcal types. Induction of transformation by a desoxirribonucleic acid fraction isolated from Pneumococcus type III. Journal of Experimental Medicine, 79(2), 137158. doi: 10.1084/jem.79.2.137

Barrionuevo, J. M. (1975). Historia de los hospitales. Hospitales de Costa Rica, 6, 17-20.

Beldarraín, E. (2015). Impact of the 1970 Reforms to Cuba's National Tuberculosis Control Program. MEDICC Review, 17(3), 33-38.

Carrillo, A. M. (2002). Economía, política y salud pública en el México porfiriano (1876-1910) Economics, Politics and Public Health in Porfirian Mexico (1876-1910). História, Ciências, SaúdeManguinhos, 9(supplement), 67-87.

Cordero, M. (2001). Las grandes epidemias en la America Colonial. Archivos de Zootecnia, 50, 597-612.

Dye, C. (2014). After 2015: Infectious diseases in a new era of health and development. Philosophical Transactions of the Royal Society of London, Biological Sciences, B 369, 20130426. doi: 10.1098/rstb.2013.0426

Fajardo-Ortiz, G., \& Ferrer-Burgos, Y. (2003). Control sanitario de las enfermedades transmisibles en hispanoamérica. Siglos XVI, XVII y XVIII. Gaceta Médica de México, 139(6), 617-621.

Fisberg, M., Kovalskys, I., Gomez, G., Rigotti, L., Cortés, Y., Herrera-Cuenca, M., . . . Eleans Study Group. (2015). Latin American Study of Nutrition and Health (ELANS): Rationale and study design.
BMC Public Health, 16, 93. doi: 10.1186/s12889016-2765-y

Flisser, A. (2009). La medicina en México hacia el siglo XX. Gaceta Médica México, 145(4), 353-356.

Franco-Paredes, C., Lammoglia, L., \& Santos-Preciado, J.I. (2004). Perspectiva histórica de la virulencia en México: Aparición, eliminación riesgo de reaparición por bioterrorismo. Gaceta Médica de México, 140(3), 321-327.

Franklin, R. E., \& Gosling, R. G. (1953). Molecular configuration in sodium thymonucleate. Nature, 171(4356), 740-741.

García, J. C. (1981). La Medicina Estatal en América Latina (1889-1930). Revista Latinoamericana de Salud, 1, 73-101.

Global Alliance for Vaccines and Immunisation. The Vaccine Alliance. (2016). Coutry Hub. Recuperado de http//:www.gavi.org

González-Mata, A., Ulloa-Gutiérrez, R., Brea, J., Soza, G., \& Tremoulet, A. H. (2013). Orígenes e importancia de la Red de Enfermedad de Kawasaki en América Latina (REKAMLATINA). Revista Chilena de Infectología, 30(4), 402-404.

González, V. L., Casanova, M. M., \& Pérez, L. J. (2011). Cólera: Historia y actualidad. Revista de Ciencias Médicas, 15(4), 280-294.

Guerra, F. (1988). Origen de las epidemias en la conquista de América. Quinto Centenario 14, 43-51.

Guimarey, L., \& Ferrero, F. (2014). Medio siglo de la Sociedad Latinoamericana de Investigación Pediátrica. Archivos Argentinos Pediatría, 112(4), 300-301.

Ham, R., Nava, I., \& Torres, A. L. (2011). Diagnóstico socio-demográfico del envejecimiento en México (Serie Documentos Técnicos). México D.F.: Consejo Nacional de Población.

Harvey, H. R. (1981). Public Health in aztec society. Bulletin of the New York Academy of Medicine, 57(2), 157-165.

Instituto Nacional de Estadística y Geografía. (2015). Principales resultados de la Encuesta Intercensal 2015. Estados Unidos Mexicanos. Aguascalientes.

International Planned Parenthood Federation. (2014). From choice, a world of possibilities. Recuperado de http://www.ippfwhr.org 
Íñiguez, L., \& Barcellos, C. (2003). Geografía y salud en América Latina: Evolución y tendencias. Revista Cubana de Salud Pública, 29(4), 330343.

Iracheta, M. P., \& Lagunas, H. (1998). El cólera morbus en cinco municipios del Estado de México, en 1850. Papeles de Población, 4(16), 149-166.

Johansson, P. (2000). Escatología y muerte en el mundo Náhuatl precolombino. Estudios de la Cultura Náhuatl, 31, 166-196.

Kac, G., \& García, J. (2010). Epidemiología de la desnutrición en Latinoamérica: Situación actual. Nutrición Hospitalaria, 25(Supl. 3), 50-56.

Kallenber, J., Mok, W., Newman, R., Nguyen, A., Rickman, T., Saxenian, H., \& Wilson, P. (2016). Gavi's Transition Policy: Moving from Development Assistance to Domestic Financing of Immunization Programs. Health Affairs, 35(2), 250-258.

López, J. M., \& Pardo, J. (1996). La influencia de Francisco Hernández (1515-1587) en la constitución de la botánica y la materia médica modernas. Valencia, España: Artes Gráficas Soler.

Malamud, C. (2014). Historia de América. Madrid, España: Alianza Editorial.

Micheli de, A., \& Izaguirre-Ávila, R. (2011). La vacunación antivariólica antes y después de Jenner. Revista de la Investigación Clínica, 63(1), 84-89.

Morgan, T. H. (1915). Localization of the Hereditary Material in the Germ Cells. Proccedings of the National Academy of Sciences of the United States of America, 1(7), 420-429

Organización Mundial de la Salud. (octubre, 2016). Cólera [Nota descriptiva]. Recuperado de http:// www.who.int/mediacentre/factsheets/fs107/es/

Organización Panamericana de la Salud. (18 de abril de 2013). Vacunación: Una responsabilidad compartida. Recuperado de http://www.paho. org/chi/index.php?option=com_content\&view $=$ article\&id=492:vacunacion-responsabilidadcompartida\&Itemid $=215$

Organización Panamericana de la Salud \& Organización Mundial de la Salud. (21 de octubre de 2016). Las Américas cumplen 25 años sin polio [Noticias]. Washington, D. C. Recuperado de http://www. paho.org/hq/index.php?option=com_content\&v iew $=$ article $\& i d=12640$ :americas-celebrate-25years-without-polio\&Itemid=1926\&lang=es

Organización Panamericana de la Salud \& Organización Mundial de la Salud. (4 de mayo de 2017). Cólera [Actualización epidemiológica]. Washington, D. C. Recuperado de http://www.paho.org/hq/ index.php?option $=\mathrm{com}$ docman\&task $=\mathrm{doc}$ view\&Itemid $=270 \& \mathrm{gid}=39838 \&$ lang $=\mathrm{es}$

Pérez, C. H., García, S. E., Pérez, C. N., \& Samper, J. A. (2009). Historia de la lucha antituberculosa. Revista Habanera de Ciencias Médicas, 8(2).

Prieto-Miranda, S. E., Jiménez-Bernardino, C. A., Guerrero-Quintero, L. G., \& Mora-Sota, M. (2012). Guadalajara en los tiempos del cólera morbus. Medicina Interna de México, 28(4), 371-373.

Pruna, P. M. (2006). Principales Descubrimientos e Invenciones en el Siglo XX. Sociedad Cubana de Historia de la Ciencia y la Tecnología y Museo Nacional de Historia de las Ciencias. La Habana. Recuperado de http:// www.schct.sld.cu/ publicaciones/SXX-Versión.pdf.

Quirós, C. (1996). La viruela en el Perú y su erradicación: recuento histórico. Revista Peruana de Epidemiología, 9(1), 41-53.

Ramírez, F. A. (2016). El cólera morbus en Guatemala: Las Juntas de Sanidad y prácticas médicas en la ciudad, 1837. Estudios Digital, 4(8), 1-21.

Ruiz, D., \& Morales, C. (2015). Social determination of the oral health-disease process: A social-historical approach in four Latin American countries. Investigación y Educación en Enfermería, 33(2), 248-259. doi:10.17533/udea. iee.v33n2a07

Salzano, F. M., \& Sans, M. (2014). Interethnic admixture and the evolution of Latin American populations. Genetics and Molecular Biology, 37(1 suppl), 151-170. doi: 10.1590/S141547572014000200003

Sánchez, J. M. (2011). Las enfermedades infecciosas en la historia humana. Ciudad LibrosRed.

Santiso, J. (2006). La economía política de lo posible en América Latina. México D.F., México: Editorial Planeta Mexicana.

Santos, V.G. (2010). Paternidad responsable: Estrategias, programas y marcos legales para su implementación. México: Centro de documentación, Información y Análisis. LXI Legislatura, Cámara de Diputados. 
Serna de la, I. (2003). La vejez desconocida: Una mirada desde la bioloigía a la cultura. Madrid, España: Ediciones Díaz de Santos.

Tovar, V., \& Bustamante, P. (2000). Historia del cólera en el mundo y México. Ciencia Ergo Sum, 7(2), 178-184.

Ulloa-Gutiérrez, R., Salgado, A. P., \& Tremoulet, A. H. (2014). Kawasaki disease in Latin American children: Past, current, and euture challenges. Journal of the Pediatric Infectious Diseases Society, 3(4), 280-281.

United Nations International Children's Emergency Fund. (2014). Vivencias y relatos sobre embarazo en adolescentes. Una aproximación a los factores culturales, sociales y emocionales a partir de un estudio en seis países de la región. (Informe final). Panamá: Autor.
Viesca-Treviño, C. (2010). Epidemias y enfermedades en tiempos de la Independencia. Revista Médica del Instituto Mexicano del Seguro Social, 48(1), 47-54.

Watson, J. D., \& Crick, F. H. (1953). Molecular structure of nucleic acids. A structure for deoxyribose nucleic acid. Nature, 171(4356), 737-738.

Williams, C., Gilbert, B., \& Zeltner, T. (2016). Effects of economic crises on population health outcomes in Latin America, 1981-2010: An ecological study. BMJ Open, 6(1), doi: 10.1136/ bmjopen-2014-007546 